\title{
Comparative Arabic and English Literacy: A Study of Female University Students' Practices in Saudi Arabia
}

\author{
Islam Ababneh \\ Department of Languages and Translation, Faculty of Education and Arts, University of Tabuk, Tabuk, Saudi Arabia \\ E-mail: iababneh@ut.edu.sa
}

Received: 06-05-2015

Published: 01-01-2016
Accepted: 19-08-2015

doi:10.7575/aiac.ijalel.v.5n.1p.1
Advance Access Published: October 2015

URL: http://dx.doi.org/10.7575/aiac.ijalel.v.5n.1p.1

\begin{abstract}
This paper presents a comparative study of Arabic and English literacy skills and practices for Saudi female university students at their homes and at their school as indicated by the students themselves using literacy questionnaires. The study did not evaluate the proficiency of the students in any aspect of the language such as phonology, vocabulary, or grammar but rather compiled students' answers to the availability of literacy resources in English and in Arabic in their homes/school and the students' practices of literacy in both languages. Data was gathered by distributing two types of questionnaires (Arabic and English) to 200 students of English major at the department of linguistics and translation at the University of Tabuk, which is a government university in Saudi Arabia. Supporting data of cultural and religious influences on literacy was obtained through the researcher's own notes and observations. The purpose of the questionnaires was to investigate mainly: the students' literacy practices and frequency of using Arabic and English and the literacy infrastructure and literacy resources available to the students at their homes and at their school. The students' answers to the questionnaires indicated that most students interacted using mainly Arabic and very little English at their homes and they used some English at their school, which is related to reading their school academic books, doing homework assignments, and having rare English conversations with their classroom teachers.
\end{abstract}

Keywords: Arabic literacy, English literacy, Saudi Arabia

\section{Introduction}

Literacy is defined by researchers as the ability to read and write in some language. The realization of linguistic knowledge into some text or spoken words defines the soci-cultural status of an individual into a larger society. Many researchers all over the world have attempted to tackle issues related to literacy by investigating lack of literacy or the mistakes made in learning and teaching literacy subjects; and then suggest possible solutions. In Saudi Arabia, the foreign language of English has taken a back seat to the Arabic native language and many in the Saudi society consider English as a language that is attached to western cultures that is opposed to their Arabic and Islamic values and way of life. The English school curriculum is very modest when compared with its Arabic counterpart. A visitor to Saudi Arabia might see that Arabic is the prevailing language among local and expatriate groups, who come to work in the country; even though, many expatriates often speak the languages of Arabic in grammatically wrong sentences. Rarely, you see English used as a communication language except among very well defined western groups within their own compounds of residence or occasionally in high academic institutions at times of international events and meetings; but lately there has been some emphasis on studying and learning English among different groups in the Saudi society. Nevertheless, many teachers in Saudi Arabia have complained about the poor English skills among university students and warned of the urgent need to tackle this literacy problem at the early learning stages for the students. Frankly, Arabic speakers perceive difficulties to pronounce some of English words since the language has more vowels than Arabic, which makes words such bed and bad hard to distinguish. Also, English patterns, word stressing, grammar (verb/tenses), and no English/Arabic cognates results in difficulties to Arabic speakers learning English.

Gained literacy skills require guidance and input from both parents at home and teachers at school. Based on international numerous literacy research papers, many factors such as the influence of the parents or the teachers affect students to learn a certain skill of a language. Street (1990) definition of literacy practices and literacy events is adopted where she hypothesized that there is a direct connection between literacy development and the cultural environment and this view of literacy as a social practice underpins this work.

Heath (1991) explained that the term 'literate behavior' as the skills, the concepts, and the thinking that an individual develops within the society and the environment shapes the views of people and as a result forms the basis of literacy as society proclaims to be.

Scribner \& Cole (1981) theorized that what people read and write on daily basis reflects their own values, beliefs, practices and assumptions and as a result influences the general lives of people within a particular society. Also, Snow .et. al (1991) proclaimed the task of literacy learning is even more daunting for those students who attempt to become literate in a school language that is not used for everyday social communication in their communities. 
Purcell-Gates \& Dahl (1991) studies have shown that children's literacy development improves more if homes engage in literacy activities and practice that support or prepare children for school literacy learning. In fact, DeBaryshe et.al (2000) referred to literacy beliefs as a "set of perceptions" internalized by parents at home in relation to literacy learning.

Leichter (1984) suggested that literacy artifacts are influential in the support and development of literacy. Examples of these literacy artifacts are: Books; dictionaries; atlases and maps; encyclopedias; school workbooks, reports, and tests; letters to and from school; newspapers; magazines; television guides; comic books; junk mail; notes from one family member to another; greeting cards...etc.

Bernhardt (1991) explained that developing reading literacy involves three variables: linguistic in terms of letter, word, and morphosyntactic knowledge, literacy in terms of knowing how to approach text and what to do with the text and knowledge in terms of having enough background knowledge to help with text comprehension

According to the Central Intelligence Agency's World Factbook 2002, the literacy rate in Saudi Arabia in 1970 was $15 \%$ for men and $2 \%$ for women but in 1990 it was $73 \%$ for men and $48 \%$ for women and, in 2002, it reached $90.9 \%$ and $70.2 \%$, respectively; but other than the official statistics, little work has been done to compare the Arabic and English literacy skills of Saudi students; also little research has been done inside the Saudi homes and Saudi schools or even in the homes and schools in the wider Arab world. In literature, there is a minimum work done on Saudi home and school literacy. Jazzar (1991) described the research in the Arab home-life and its impact on literacy done in the Arab world as "limited and shallow". Shannon (2003) pointed out the fact that Gulf culture still retains strong elements of its oral tradition and that family members read very little in Arabic and less in English and that makes the development of reading among children within the socio-cultural environment challenging. Ibrahim. et. al (2002) study looked at the acquisition of literacy in Arabic, Hebrew and English and found that word recognition time for English words is shorter than the other two languages and longest for Arabic words. Thus, this research is an attempt of an important investigation of the literacy lives of Saudi students in two languages, Arabic and English.

Almusa (2003) explained that Arabic is a diglossic language, which refers to a situation where two varieties of the same language are used for socially distinct functions. " Alfusha" is the modern standard Arabic, a modern descendent of Classical Arabic, used for writing and formal speech in news broadcasts and religious sermons while "Alammiyya" is used for daily conversation and social interaction comprises a multitude of local and ethnic vernaculars that are used for everyday conversation of people in the Arabic world of twenty two countries. The use of a spoken vs. standard variety of Arabic for mutually exclusive sets of functions has distanced the two forms from each other. The distance is apparent in all linguistic domains, including lexicon, syntax, morphology and phonology. Saudi people use the "Alammiyya" with their own local dialect to communicate in their homes and local environment. The dialect may vary from a region to another within the country of Saudi Arabia.

\section{Method}

The study compares the Arabic and English literacy for girl students in a government university in the Tabuk region of Saudi Arabia, where the native language is Arabic; but, the study does not investigate students' competence in any language. The study was conducted on a group of students from the University of Tabuk (girls section) and the results obtained only reflected the practice of those inquired girl students within their limited university environment. The students were all of Saudi nationality who have lived in the northern part of Saudi Arabia for all their lives and attended mostly government schools or even private Arabic Saudi schools, where the language of instruction inside the classrooms is Arabic, the language spoken at Saudi homes. The formal Arabic (Fusha) is normally not used for normal conversation but rather found in textbooks and official documents. Therefore, the sample was a biased one since the study majors for the students was the English language. The socioeconomic status of the families was similar and was classified to be of average socioeconomic status in the Saudi society. The fathers of the students were mostly government employed or business people owning private shops and employing foreign workers. The mothers were mostly full time housewives dedicated to raising their children and were depended on their husbands for movement and providence. Thus, all the students embraced the same religion, culture, and came from a similar background.

For data collection, two questionnaires were distributed to 200 third and fourth year English major students in the department of English and translation (female section) inside their classrooms. The questionnaires were divided into three categories: 1) general Arabic/English use (speaking, reading, and writing) at home and at school, 2) Arabic/English availability of artifacts at home and at school, and 3) specific Arabic/English literacy practices at home and at school. The questionnaires asked the students to classify the availability of an Arabic/English resource or the frequency of their practice of Arabic/English activities into one of four selections: always, usually, hardly, or never. Then the collected data was quantitatively categorized and interpreted. The "always" and "usually" answers were combined to represent a strong availability of a resource or a strong practice of an activity; while the "hardly" and "never" answers were combined to represent a weak availability of a resource or a weak practice of an activity. The students were given ample time to answer their use of Arabic/English in their homes and school and whether Arabic/English artifacts were available to them in both environments. The content of the literacy resources nor the specific information in the available resources in both languages was investigated.

\section{Results and Discussions}

Most of the students pointed out to have limited available Arabic/English resources at home and at school that helped them improve their Arabic/English literacy and they performed minor English literacy activities besides their school 
work. Also, many students added that their parents and family members at home spoke to them in Arabic and the parents were unable to help them in English conversations. Many of the students answered to practice reading islamic stories and reciting the holy book (Quran) in their homes with their siblings and parents only in Arabic and not in English

First, the students answered that they spoke/listened to a lot more Arabic than English even though they read/wrote similar percentage of Arabic and English. Figure 1 shows that more than $90 \%$ of the students "always" or "usually" spoke/listened to Arabic at their homes and on average 70\% of them answered they "always" or "usually" wrote/read Arabic at home. The blue color bars in figure 1 refer to the combined "always" and "usually" frequency that represent a strong indicator of the activity while the red color bars are the combined "hardly" and "never", which represents a weak indicator of the activity. Figure 2 shows that a good percentage of around $65 \%$ of students answered that they "always" or "usually" listened, wrote, and read some English at home; meaning 35\% of them answered that they "hardly" or "never" listened, wrote, or read English at home. Also, figure 2 shows that only around $13 \%$ of the students answered they "always" or "usually" spoke English inside their home environment; meaning 87\% of the students "hardly" or "never" spoke English at home. Speaking was defined to the students as structuring words into meaningful sentences to asking for something from a family member or explaining an idea in few sentences; in other words, speaking was not defined to performing heavy use of the language in continuous lengthy interactions. The specifics of what the students wrote/read/listened in Arabic/English cannot be known from only figure 1 and figure 2 and the details of any conversation that took place at home/school was not looked into or asked about in the questionnaires. In short, The students spoke mostly Arabic at home while they read/wrote/listened to mix of Arabic and English at their homes. In addition to interactions with family members, the media sources such as the Internet, TV, Radio...etc are all valid sources of the language that the students might have listened to at their homes.

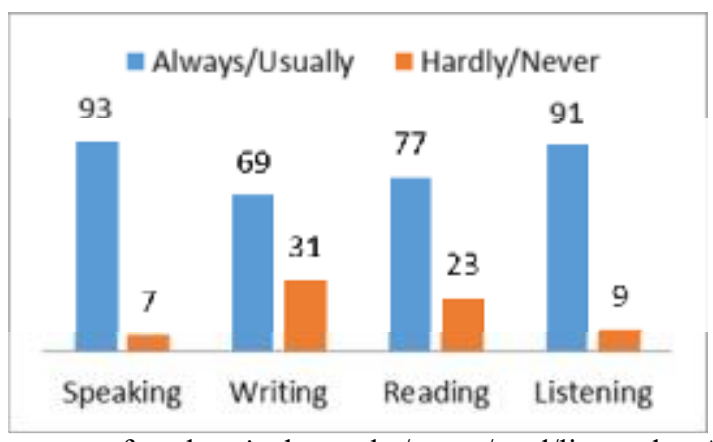

Figure 1. Percentages of students' who spoke/wrote/read/listened to Arabic at home

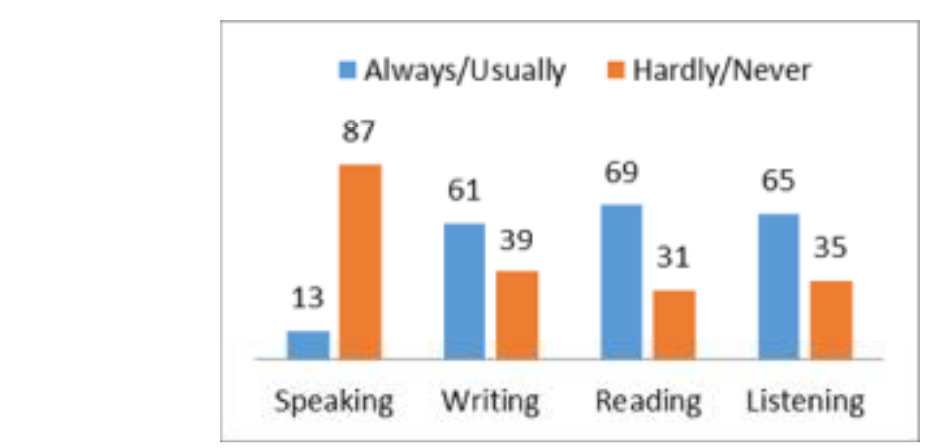

Figure 2. Percentages of students' who spoke/wrote/read/listened to English at home

Second, in answering about their school literacy activities, the students indicated that they spoke more Arabic than English inside their school even though they read/wrote/listened to more English than Arabic; probably because English is the language of instruction in the department of languages and translation and the instructors are bound to communicate using English inside the classrooms. The students spent the majority of their time at school attending classes, which implies that the students were affected by academic literacy more than any social practice within their school environment. Figure 3 shows that $85 \%$ of the students "always" or "usually" spoke Arabic in the school while only around $30 \%$ of them "always" or "usually" wrote/read Arabic within their school environment. Thus, the students spoke and listened in similar percentages to Arabic at home and at school while they wrote and read more Arabic than English in their homes. Figure 4 shows that around $88 \%$ of students answered that they "always" or "usually" wrote,/read,/listened to English at school while a good percentages of the students (55\%) answered they "always" or "usually" communicated using English inside the school environment; which means 45\% of the students "hardly" or "never" spoke English at school. Again, the degree of how much speech, listening, reading, or writing was not measured or asked about in the questionnaires. 


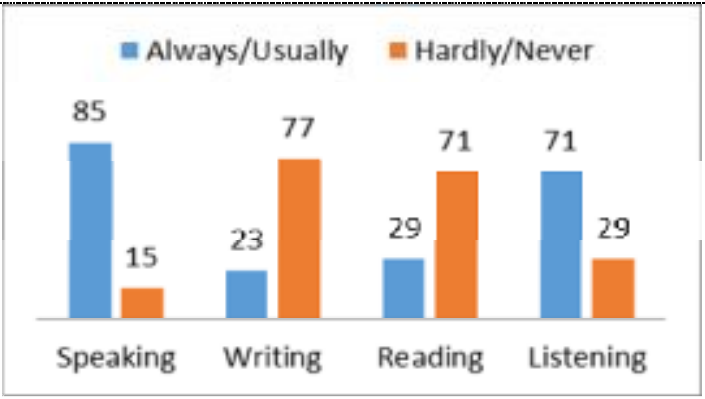

Figure 3. Percentages of students who spoke/wrote/read/listened to Arabic at school

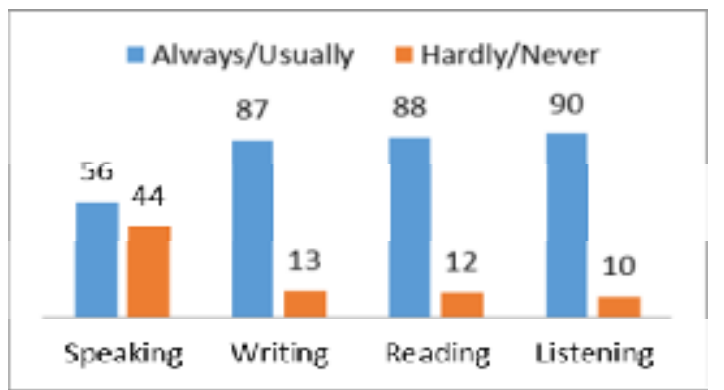

Figure 4. Percentages of students' who spoke/wrote/read/listened to English at school

Therefore, higher percentage of the students interacted using English in the school than at home. Also, as observed by the researcher, the students spoke English with their school teachers in discussing academic related material as required by the department but they used Arabic to socially interact with other students inside the school premises. Gardner \& Macintyre (1991) proposed that the motivation to learn the language could involve attitudes toward the concerned community and also the attitude toward the learning situation., which may involve attitude toward the instructor, class, textbooks, language laboratory etc. Laine (1977) investigated some students learning English and found that indicators of self-confidence and motivation had association with English achievement.

Third, in order to investigate the literacy enriching resources behind more perceived Arabic literacy than English literacy, the next part in the two questionnaires asked about resources available to the students at their homes/school. The students answered to have similar type of resources for their Arabic or English literacy. The students had available a computer, story books, and the Internet that were used equally in both languages; but they had more academic books and a dictionary in English and islamic books in Arabic. The availability of a literacy resource does not indicate the degree of its usage as it might have been used by other family members living in the same home. Figure 5 shows academic books and the dictionary, were "always" or "usually" available to $75 \%$ of the students in English; while a good percentage of the students had a computer and English story books. Figure 6 show that $50 \%$ or more of the students "always" or "usually" had islamic books, story books, or the Internet in Arabic. Some faculty members in the English department at Tabuk University have indicated in internal unpublished reports the need to include islamic concepts and objectives, retraining of teachers, rewriting syllabuses and textbooks with more use of English. In that regard, involving islamic teaching using the English language will encourage students to learn English while gaining their essential islamic knowledge. In this survey, other resources such as the library, DVDs, magazines, and newspapers were "always" or "usually" available to less than $30 \%$ of the students in both languages and such resources most likely had little effects on the majority of students' literacy skills. It must be noted that women's movement in the Saudi culture is limited and is done with the help of a male family member or some male driver, which can make for example visiting a public library or a book store harder for a female student than for a male student. It is also interesting to denote that the students "always" or "usually" watched video tapes with higher percentage in English than in Arabic.

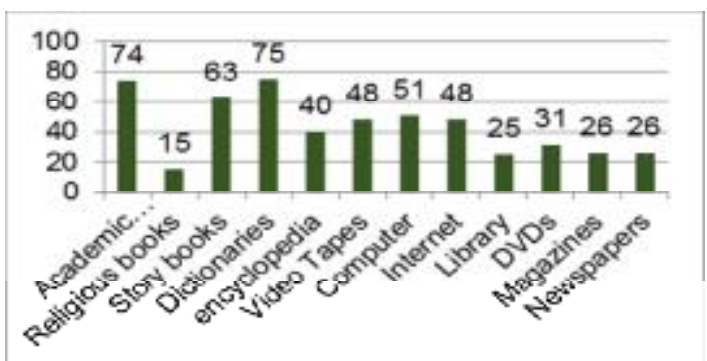

Figure 5. Percentages of students who "always" or "usually" had some English artifacts 


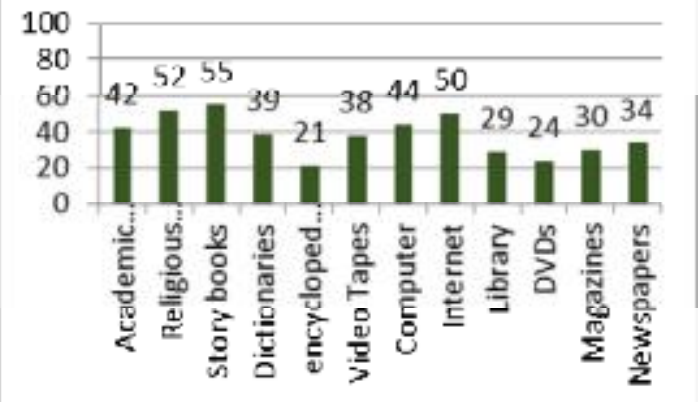

Figure 6. Percentages of students who "always" or "usually" had some Arabic artifacts

To sum up, the above two figures indicate that most of the students' literacy in Arabic/English came from mostly limited resources of academic books, islamic and story books, and a computer with Internet connection. The utilization of some of the literacy resources was realistically expected and confirmed by students' answers since the students were of English major and had to use academic books, computers, and dictionaries in English for their academic studies but they had the choice to use other resources for their pleasure and entertainment in other languages and they probably used these resources in their mother tongue of Arabic at their free time at home.

Figure 7 shows the English activities that were "always" or "usually" practiced by more than $50 \%$ of the students surveyed. It is clear that these practices were related to the students' academic studies such as reading English textbooks, doing homework and exercises, reading with a group, and discussing some English topics. The only non academic activity that was performed by more than $50 \%$ of the students was watching some English movies, which was mainly done for pleasure with Arabic subtitles as proclaimed verbally by a good number of the students. Figure 8 shows the activities that were answered to be "always" or "usually" practiced by $49 \%$ or less of the students in English. These activities were related to social interactions and entertainment such as reading magazines and newspapers, doing puzzles, and having a conversation with others. Some activities such as drama were performed by $49 \%$ of the students taking drama classes as required by the department for English major as there are few drama classes offered by the department and are part of the students' English curriculum requirements.

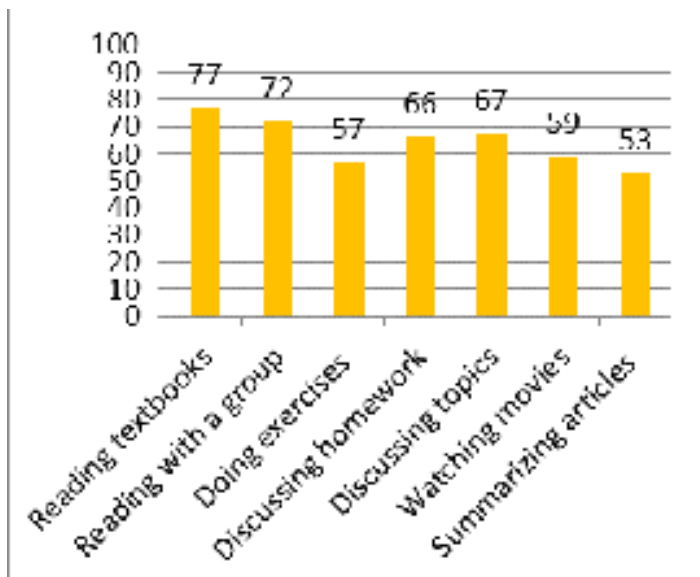

Figure 7. Practices that were "always" or "usually" performed by more than $50 \%$ of the students in English

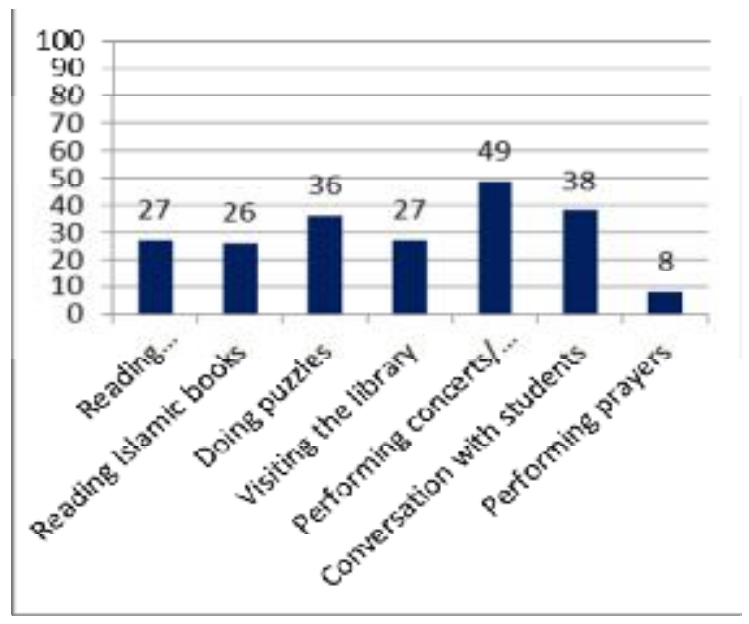

Figure 8. Practices that were "always" or "usually" performed by $49 \%$ or less of the students in English 
Figure 9 shows that the same activities such as reading textbooks, doing homework and exercises, and summarizing articles that were practiced by more than $50 \%$ of the students in English (as shown in figure 7) were practiced by less than $50 \%$ of the students in Arabic (on an average of $40 \%$ ). Again, most of these activities were related to school work. Also, it can also be inferred that the majority of students were more inclined to practice their literacy in only one language and not both. For example, $77 \%$ of the students read textbooks in English compared to only $29 \%$ of the students who read textbooks in Arabic, which might be an Arabic translation of their English textbooks.

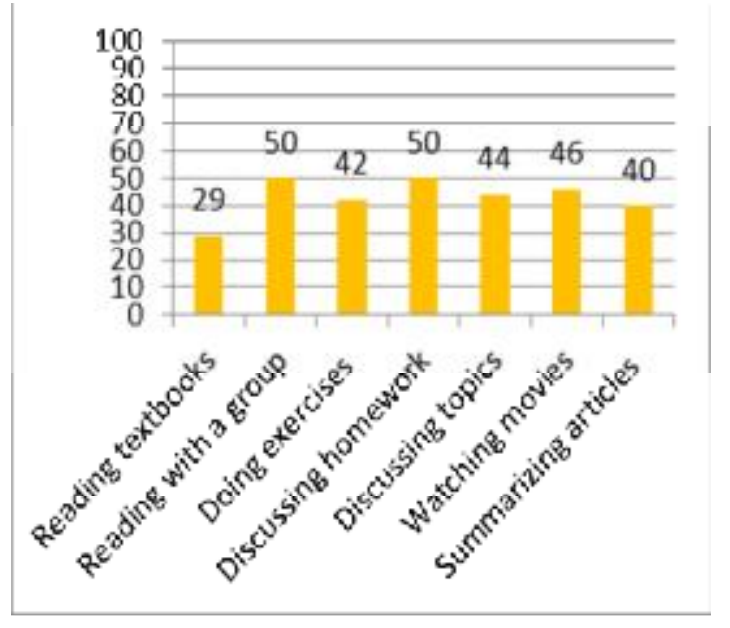

Figure 9. Practices that were "always" or "usually" performed by 50\% or less of the students in Arabic.

Also, figure 10 shows that an average of $50 \%$ of the students performed activities related to their islamic faith such as studying the life and deeds of the prophet Muhammad (pbuh) in Arabic; of course, the students, as all Muslims, perform prayers only in Arabic as they are required to utter Quranic verses in Arabic while praying. Living within an islamic society, $52 \%$ students answered to have performed their religious reflections, meditations, and islamic remembrances in Arabic compared to only $8 \%$ who indicated to have used English for such activities. Also, 52\% of students read islamic books in Arabic compared to only 26\% who read islamic books in English.

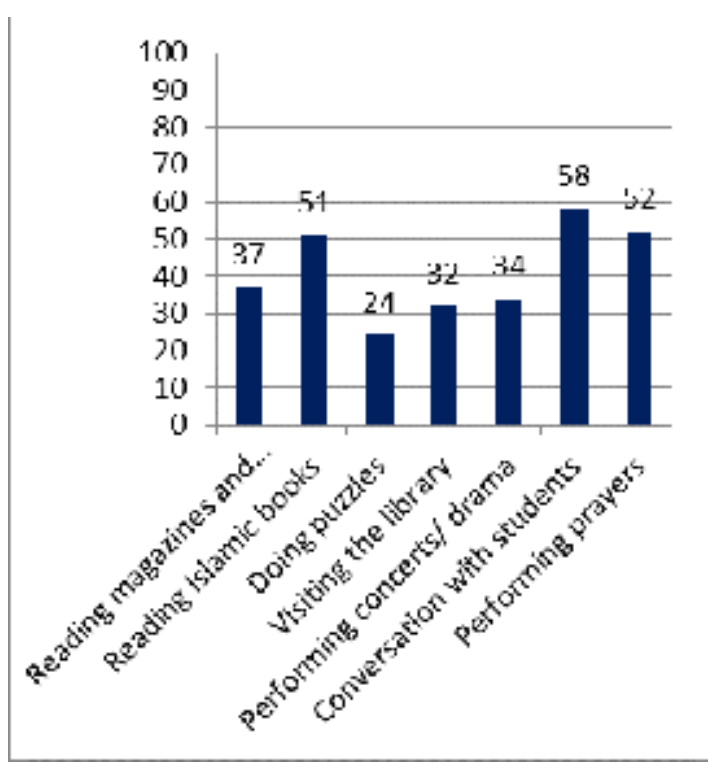

Figure 10. Practices that were "always" or "usually" performed by $60 \%$ or less of the students in Arabic.

Finally, not performing an activity in Arabic does not mean the same activity is necessarily performed in English and vice versa; it could simply mean the activity is not performed at all. For example, activities such as doing puzzles and visiting the library were done by a small percentage of around $30 \%$ or less of the students in any language, which means many students did not perform those activities at all in any language. Also, if the students had certain literacy resource at home/school did not imply they had to use it to improve their literacy skills. Also, how much of cultural influence were the students exposed to within their Saudi society was not deeply examined since such an investigation would need lengthy home visits and observations. In addition, how much the students believed of the importance of learning a second language was not the focus of this research. 


\section{Conclusion}

Briefly, based on surveyed students' answers, it can be deduced that the focus students who were of English major at the University of Tabuk in Saudi Arabia might have read, written, or listened to some English at their homes or at their school but they rarely spoke the language with anyone other than their school teachers. Even though all students surveyed were taking English classes inside an English instructional college, most of them mentioned to use little English in their homes and school other than doing their textbooks readings, writing their homework assignments, and/or watching English movies with Arabic subtitles. When asked to elaborate on some answers given in the survey, the students orally explained that islamic and cultural factors influenced them to practice certain literacy skills only in Arabic such as reading the Quran and its translation. Reading the Quran and the prophets' life and ways is considered essential to learning good moral values for a Muslim in Saudi Arabia and in other parts of the world as well. Also, reciting the Quran must be in Arabic and many Muslims consider learning the language crucial to appreciating the beauty of its content. On the other hands, some students still read islamic stories in English and that might be to increase their English vocabulary and terms. The availability of literacy resources in both languages was not a major disparity to literacy acquisition as the students used similar resources to gain literacy in both languages. Therefore, it is also possible to perceive that other factors such as the Saudi socio-economic, background factors, home and school factors are all valid influencing factors of the low English utilization that make the students use Arabic in religious and cultural contexts far more than English and must be further investigated. The students elaborated that their home environment naturally drove them to lag behind in their English literacy when compared to the rich Arabic home environment. Thus, researchers who study Saudi literacy should look into the social, cultural, and motivational issues that impact learning English by Arab natives. Specifically, future research should shed some light on the challenges of Arab Saudi natives to acquire a second language such as English. Also, the management of Saudi universities should look at including English content into islamic and Arabic courses in the university's curricula. In closing, the results presented in this paper can only be substantiated by more extensive insights into the lives of a larger sample from both genders and by involving more homes and schools into future studies of literacy in Saudi Arabia.

\section{Acknowledgment}

The author would like to acknowledge financial support of this work from the Deanship of Scientific Research (DSR), University of Tabuk, Tabuk, Saudi Arabia, under grant no. S/0094/1436

\section{References}

Almusa, N. (2003). Altunaiyat fe kadaya alluga alarabiya min asr alnahda ela asr alawlama [Dual issues on Arabic from the enlightenment period to the period of globalization]. Jordan, Alshuruk Post . (in Arabic).

Bernhardt, E. B. (1991). Reading development in a second-language. Norwood, NJ: Ablex.

DeBaryshe, B.C., Binder, J.C., \& Buell, M.J. (2000) Mothers' implicit theories of early literacy instruction: Implications for children's reading and writing. Early Child Development and Care, 160, 119-131.

Gardner, R.C. \& Macintyre, P.D. (1991). An instrumental motivation in language study: who says it isn't effective? Studies in Second Language Acquisition, 13, 57-72.

Heath, S. B. (1991). A lot of talk about nothing. In B. M. Power and R. Hubbard (Eds.), The Heinemann reader: Literacy in process (pp. 79-89). Portsmouth, NH: Heinemann.

Ibrahim, R. Eviatar, Z., \& Aharon-Peratz, J. (2002). The Characteristics of Arabic Orthography Slow its Processing. Neuropsychology, 16(3), 322- 326.

Jazzar, M.R. (1991). A probe into Arab home literacy and its impact on college students' reading ability in Arabic and English. PhD thesis. Indiana University.

Laine, E. (1977). Foreign language learning motivation in Finland I, Turku: Turku University Press.

Leichter, H. J. (1984). Families as environments for literacy. Awakening to literacy, 38, 50.

Purcell-Gates, V., \& Dahl, K. L. (1991). Low-SES children's success and failure at early literacy learning in skill-based classrooms. Journal of Reading Behavior, 23, 134-140.

Scribner, S., \& Cole, M. (1981). The psychology of Literacy. Cambridge: Harvard University Press.

Shannon, J. (2003). Getting Gulf students to enjoy reading. In Perspectives. 11(1), 21-24.

Snow, C. E., Barnes, W. S., Chandler, J., Goodman, I. F., \& Hemphill, L. (1991). Unfulfilled expectations: Home and school influences on literacy. Cambridge, MA: Harvard University Press.

Street, B. (ed.). (1990). Literacy in development: people, language, and power. London: Commonwealth Institute. 